\title{
CINÉTICA DE HIDRATAÇÃO E DA LIBERAÇÃO DE SÓLIDOS SOLÚVEIS DO MILHO GENETICAMENTE MODIFICADO E DE SUA ISOLINHA
}

\author{
B. C. MARQUES ${ }^{1}$, L. M. M. JORGE ${ }^{2}$, R. M. M. JORGE ${ }^{3 *}$ \\ ${ }^{1,3}$ Universidade Federal do Paraná, Departamento de Engenharia Química, Programa \\ de Pós-graduação em Engenharia de Alimentos, Av. Cel. Francisco H dos Santos, s/n, Jardim \\ das Américas, CEP: 81530-900 - Curitiba - PR - Brasil \\ ${ }^{2}$ Universidade Estadual de Maringá, Departamento de Engenharia Química, CEP 87020-900 \\ - Maringá - PR - Brasil \\ *E-mail para contato: rjorge@ufpr.br
}

\begin{abstract}
RESUMO - A hidratação dos grãos de milho realizada na indústria alimentícia para o processo de moagem úmida tem como principal objetivo a obtenção do amido. Neste trabalho foi estudada a cinética de absorção de água do grão de milho transgênico cultivar 2B587 Hx e sua isolinha cultivar 2B587. As amostras foram obtidas em experimentos conduzidos pelo Programa Milho do Instituto Agronômico de Campinas (IAC/APTA) na safrinha 2012. As isotermas de absorção de água dos grãos foram modeladas pelo modelo de parâmetros concentrados nas temperaturas de imersão de 40, 50,60 e $67^{\circ} \mathrm{C}$. Verificou-se que a velocidade de absorção de água aumentou com a elevação da temperatura. Além disto, foi avaliada a cinética da liberação de sólidos solúveis na água de hidratação. Os resultados mostraram que os modelos cinéticos apresentaram boa qualidade de ajuste aos dados experimentais, destacando-se que a temperatura de imersão exerceu forte influência na liberação de sólidos solúveis durante a hidratação dos grãos.
\end{abstract}

\section{INTRODUÇÃO}

Em processos na indústria como a moagem úmida os grãos de milhos são primeiramente imersos em solução contendo 0.1-0.2 \% de dióxido de enxofre (agente antimicrobiano) e 0.5$1.5 \%$ de ácido lático em temperaturas que variam de 45 a $55^{\circ} \mathrm{C}$. Os grãos podem permanecer imersos por tempos que podem variar de 24 a $60 \mathrm{~h}$ para auxiliar a separação do amido e da proteína. A etapa de hidratação esta relacionada com a qualidade dos subprodutos do milho (germe, proteína, fibra e amido), pois com o amolecimento do grão, ocorre melhora da difusão dos outros dois solutos e ativação de enzimas. Além disto, o processo físico da moagem é favorecido (Lopes Filho et al., 2006; Pérez et al,. 2001; Shandera e Jackson, 1996).

O milho Bt (Zea mays L.) é aquele que tem sido modificado geneticamente para expressar o gene crylAb da bactéria Bacillus thuringiensis (Bt) e produzir toxinas para controlar a infestação de pestes da ordem lepidópteras (Saxena e Stotzky, 2001). No Brasil na safra de 2013/14 foram disponibilizadas 253 cultivares transgênicas e 214 cultivares convencionais, sendo que pela primeira vez o número de cultivares transgênicas superou o número de cultivares convencionais (Cruz et al., 2014). 
Modelos cinéticos têm sido utilizados para prever o tempo de hidratação do grão para obter o teor de umidade desejado em uma determinada temperatura. Para o estudo do processo de hidratação dos grãos têm sido utilizados modelos empíricos e fenomenológicos (Peleg, 1988; Omoto et al., 2009). Neste trabalho foram estudadas as características da hidratação de grão de milho transgênico e de sua isolinha convencional simulando condições industriais. Para isto, foi utilizado o modelo fenomenológico de parâmetros concentrados de Omoto et al. (2009) para o estudo da hidratação dos grãos de milhos. Também foi estudada a liberação de sólidos solúveis durante o processo utilizando-se modelo cinético de ordem zero.

\section{MATERIAIS E MÉTODOS}

Para os experimentos foram utilizados grãos de milhos transgênicos cv. 2B587 Hx e sua isolinha convencional cv. 2B587. As amostras foram obtidas em experimentos conduzidos pelo Programa Milho do Instituto Agronômico de Campinas (IAC/APTA) na safrinha 2012, no município de Cândido Mota. Os grãos foram selecionados a fim de obter grãos de tamanhos mais uniformes e eliminar grãos defeituosos. A análise da composição química das amostras foi realizada de acordo com a AOAC (1995) para a determinação do conteúdo de umidade (base seca), proteína pelo método micro-Kjeldahl ( $\mathrm{N}$ x 6,25) lipídeos (solvente éter etílico) e cinzas. As fibras brutas foram determinadas conforme procedimentos do Instituto Adolfo Lutz (2008). Os carboidratos foram calculados por diferença em base seca (carboidratos $\%=100$ - [umidade $\%+$ proteína $\%+$ lipídeos $\%+$ cinzas $\%+$ fibras brutas $\%]$ ). As determinações foram feitas em triplicatas

Os ensaios de hidratação foram realizados em temperaturas de 40, 50, 60 e $67{ }^{\circ} \mathrm{C}$ em banho termostático com agitação de $70 \mathrm{rpm}$. No banho termostático foram colocados frascos herméticos de $500 \mathrm{~mL}$ contendo $300 \mathrm{ml}$ de solução com $0,20 \%$ de dióxido de enxofre $\left(\mathrm{SO}_{2}\right)$ e $0,55 \%$ de ácido lático. A solução foi obtida adicionando-se $11 \mathrm{ml}$ de ácido lático e 5,9 g de metabissulfito de sódio em $2000 \mathrm{ml}$ de água destilada, conforme procedimento de Lopes Filho, Ramos e Romero (2006). Posteriormente, foram adicionados $160 \mathrm{~g}$ de grãos de milho aos frascos. Os ensaios foram realizados em duplicatas. Amostras foram retiradas dos frascos em tempos pré-determinados e a água superficial de cada amostra foi retirada com papel toalha. Em seguida avaliou-se a umidade, densidade aparente e a concentração mássica de água nos grãos. A umidade foi obtida através do método de estufa a $105^{\circ} \mathrm{C}$ até peso constante (Instituto Adolfo Lutz, 1985) e calculado conforme a Equações 1.

$$
X_{b u}=\frac{M U-M S}{M U}
$$

Outra parte da amostra foi destinada para determinação da densidade na qual foi registrada a massa e o número de grãos e em seguida foram transferidos para uma proveta graduada contendo água destilada. O volume da água deslocado em proveta foi utilizado para determinar a densidade do milho $\left(\rho_{\text {milho}}\right)$. Posteriormente, calculou-se a concentração mássica de água nos grãos através da Equação 2. Também foi calculado o raio dos grãos, para isto o valor obtido do volume deslocado na proveta graduada foi dividido pelo número dos grãos na proveta para obter o volume de um grão. Com isto, foi calculado o raio dos grãos considerando-os partículas esféricas obtendo-se $r_{o}$ médio de $0,37 \mathrm{~cm}$ para os dois milhos.

$$
\rho_{A}=X_{b u} \cdot \rho_{\text {milho }}
$$




\subsection{Modelagem Matemática Da Cinética De Absorção de Água}

Para o estudo da absorção de água pelos milhos foi utilizado o modelo de Omoto et al. (2009) que consiste na Equação 3, obtido por balanço de massa em regime transiente isotérmico para a água contida no grão. Para isto, considerou-se concentração de água homogênea dentro do grão, volume constante e geometria esférica.

$$
\frac{d\left(\rho_{A}\right)}{d t}=\frac{K_{S}}{r_{0}}\left(\rho_{\text {Aeq }}-\rho_{A}\right)
$$

Esta equação possui dois parâmetros ajustáveis sendo eles o coeficiente de transferência de massa aparente $\left(K_{s}\right)$ e a concentração mássica de equilíbrio $\left(\rho_{\text {Aeq }}\right)$. Foi adotado como condição inicial que no início da hidratação $\mathrm{t}=0$, a concentração de água no grão é uniforme e conhecida, $\rho_{\mathrm{A}}=\rho_{\mathrm{Ao}}$. Após a integração da Equação 3 foi obtida a forma analítica conforme apresentada pela Equação 4 sendo o parâmetro $K_{\mathrm{s}}$ obtido por regressão linear. Para isto, foi utilizado $\rho_{\text {Aeq }}$ obtido experimentalmente.

$$
\ln \frac{\left(\rho_{\text {Aeq }}-\rho_{A}\right)}{\left(\rho_{\text {Aeq }}-\rho_{A 0}\right)}=-\frac{3 K_{S}}{r_{0}} \cdot t
$$

\subsection{Análise da Água de Hidratação}

A análise dos sólidos solúveis durante a hidratação na água de imersão dos milhos foram baseadas em procedimentos realisados por Bayram et al. (2004). Para isto, alíquotas da água de imersão dos milhos foram retiradas em tempos pré-determinados mantendo-se a proporção água/produto e as análises foram realizadas com as alíquotas em temperatura de $25^{\circ} \mathrm{C}$. Para determinação dos sólidos solúveis utilizou-se refratômetro (RL3, PZOG warszawa). As análises foram realizadas em duplicatas.

\subsection{Modelo Para a Análise Dos Sólidos Solúveis}

A perda de sólidos durante a hidratação dos grãos foi descrita como a interação de água com moléculas hidrofílicas dentro da matriz do grão, liberando algumas delas na água do processo. Por isto o fenômeno de liberação de sólidos foi avaliado com a abordagem da cinética de reação. A equação cinética utilizada para o estudo da liberação de sólidos foi o modelo de ordem zero, conforme indicada na Equação 5 (SAYAR et al., 2011).

$$
\frac{d M_{d s}}{d t}=k_{d s}
$$

Integrando e rearranjando a Equação 5 foi obtida a Equação 6.

$$
M_{d s}=k_{d s} t
$$

\section{RESULTADOS E DISCUSSÕES}

\subsection{Modelo para a Análise da Cinética de Hidratação dos Grãos}


O milho geneticamente modificado cultivar 2B587 $\mathrm{Hx}$ apresentou maior quantidade de carboidratos (2B587 $\mathrm{Hx}=75,3 \%$ e 2B587=74,7 \%) e cinzas $(2 \mathrm{~B} 587 \mathrm{Hx}=1,08$ e 2B587=0,96\%) e menor quantidade de fibras brutas $(2 \mathrm{~B} 587 \mathrm{Hx}=1 \%$ e $2 \mathrm{~B} 587=1,51 \%)$ em relação ao milho convencional 2B587 ( $\mathrm{p}<0,05)$. Balieiro Neto et al (2011) também observaram diferenças na composição química entre milhos transgênicos e suas isolinhas convencionais no primeiro quando ano os danos provocados pelas condições ambientais e infestação de insetos na lavoura foram altos. Uma variedade transgênica estudada pelos autores apresentou menor teor de fibras e maior teor de carboidratos não fibrosos em relação a sua isolinha convencional. Já a outra variedade transgênica apresentou maior teor de $\mathrm{Ca}$ e $\mathrm{K}$ em relação a sua isolinha. Porém no segundo ano quando os danos foram menores as composições foram equivalentes.

Na Figura 1 pode-se observar as isotermas de hidratação dos milhos 2B587 e 2B587 Hx nas quatro temperaturas de imersão. Verifica-se que no início ocorre rápida absorção de água pelos grãos e que posteriormente diminui ao aproximar-se de condições de equilíbrio. Com a elevação da temperatura a velocidade de absorção se intensifica e os grãos atingem as condições de equilíbrio mais rapidamente.
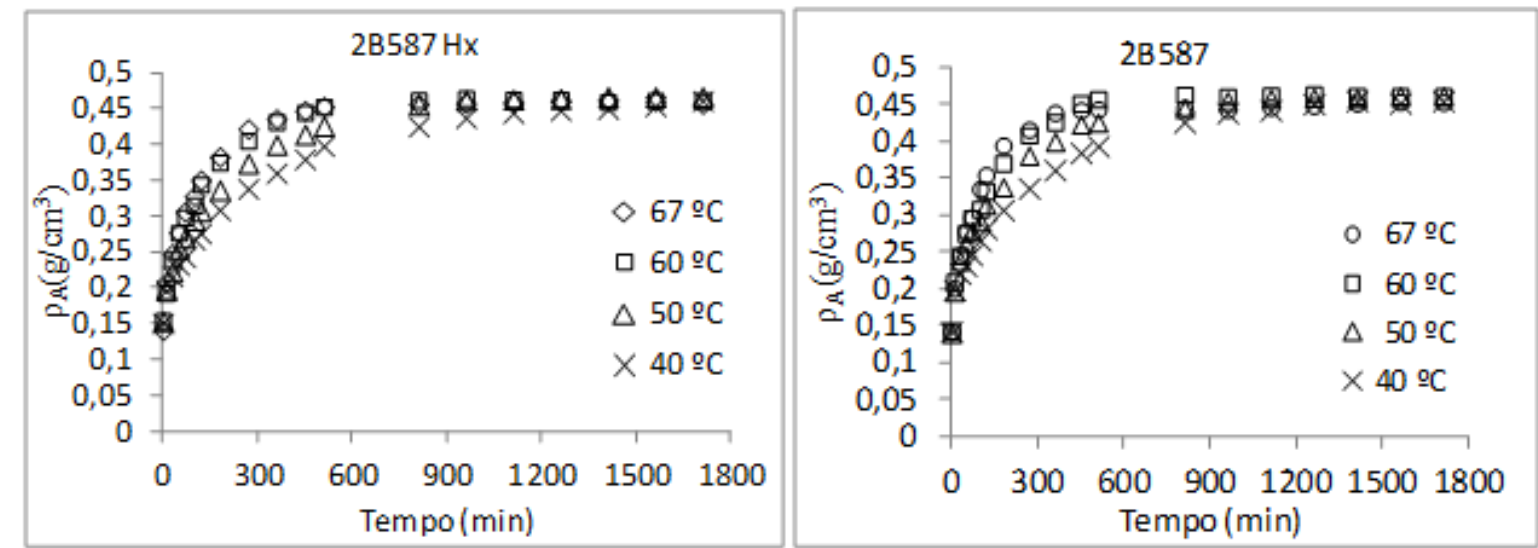

Figura 1 - Isotermas de absorção de água dos milhos 2B587 e 2B587 Hx nas temperaturas de 40, 50,60 e $67^{\circ} \mathrm{C}$

Na Tabela 1 são apresentadas as concentrações mássicas de equilíbrio $\left(\rho_{\text {Aeq }}\right)$ obtidas para os dois milhos nas quatro temperaturas. Observou-se que a concentração mássica de equilíbrio $\left(\rho_{\text {Aeq }}\right)$ não apresentou variação significativa na faixa de temperatura estudada e o milho convencional $2 \mathrm{~B} 587$ obteve valor médio de $0,4577 \mathrm{~g} / \mathrm{cm}^{3}$ e o milho transgênico $2 \mathrm{~B} 587 \mathrm{Hx}$ foi de $0,4614 \mathrm{~g} / \mathrm{cm}^{3}$. Estes valores de $\rho_{\text {Aeq }}$ médios foram utilizados na Equação 4 para obtenção do parâmetro $K_{s}$ que foi obtido por meio de regressão linear para cada temperatura, conforme mostrado na Figura 2 .

Tabela 1 - Concentrações mássicas de equilíbrio dos dois milhos nas quatro temperaturas de imersão

\begin{tabular}{ccc}
\hline Temperatura $\left({ }^{\circ} \mathrm{C}\right)$ & $2 \mathrm{~B} 587$ & $2 \mathrm{~B} 587 \mathrm{Hx}$ \\
& $\rho_{\text {Aeq }}\left(\mathrm{g} / \mathrm{cm}^{3}\right)$ & $\rho_{\text {Aeq }}\left(\mathrm{g} / \mathrm{cm}^{3}\right)$ \\
\hline 40 & $0,4550 \pm 0,0002$ & $0,4610 \pm 0,0038$ \\
50 & $0,4614 \pm 0,0059$ & $0,4665 \pm 0,0024$ \\
\hline
\end{tabular}



60
$0,4614 \pm 0,0025$
$0,4611 \pm 0,0024$
67
$0,4531 \pm 0,0039$
$0,4570 \pm 0,0021$
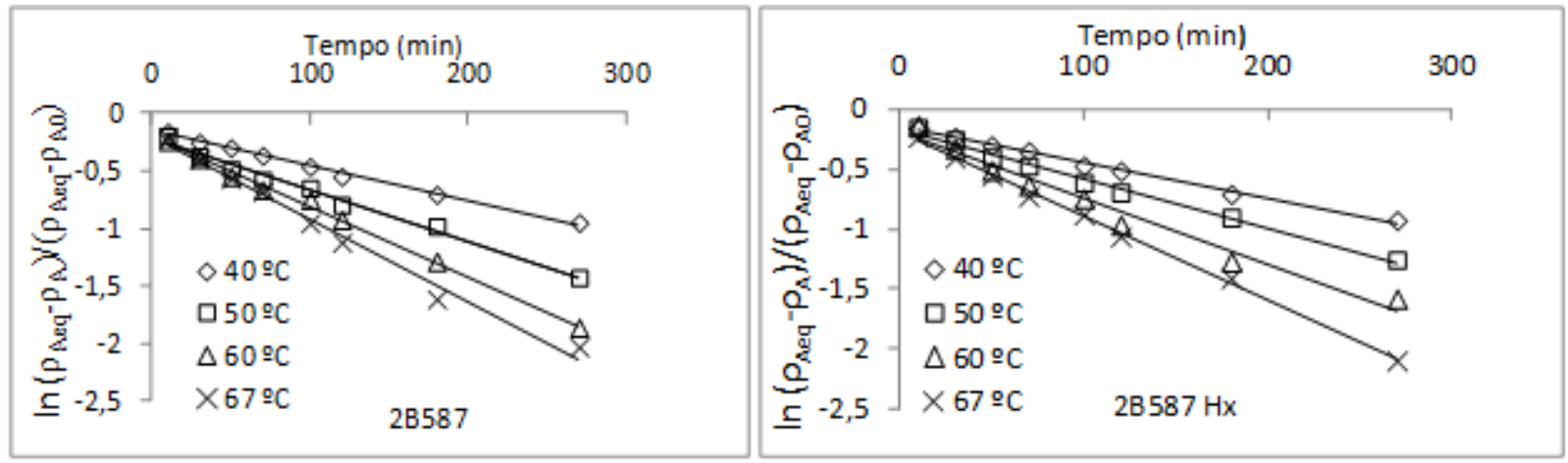

Figura 2 - Ajuste do modelo de Parâmetros concentrados aos dados experimentais para os dois milhos em cada temperatura.

A Tabela 2 mostra os valores obtidos dos coeficientes de difusão $\left(K_{s}\right)$ para os dois milhos. Os valores do parâmetro $\mathrm{K}_{\mathrm{s}}$ aumentaram com a elevação da temperatura indicando aumento da velocidade inicial de absorção de água dos grãos em temperaturas mais altas. $\mathrm{O}$ milho convencional 2B587 obteve mesmo valor de $\mathrm{K}_{\mathrm{s}}$ na temperatura de $40^{\circ} \mathrm{C}$ e com a elevação da temperatura os valores foram maiores com diferença média de $7 \%$ em relação ao transgênico. Os valores de $\mathrm{R}^{2}$ variaram de 0,9709 a 0,9977 indicando adequado ajuste do modelo.

Tabela 2 - Coeficientes de difusão $\left(\mathrm{K}_{\mathrm{s}}\right)$ dos milhos com seus respectivos coeficientes de determinação $\left(\mathrm{R}^{2}\right)$

\begin{tabular}{|c|c|c|c|c|}
\hline Temperatura $\left({ }^{\circ} \mathrm{C}\right)$ & \multicolumn{2}{|c|}{$2 \mathrm{~B} 587$} & \multicolumn{2}{c|}{$2 \mathrm{~B} 587 \mathrm{Hx}$} \\
& $\mathrm{K}_{\mathrm{s}}\left(\mathrm{cm}^{2} / \mathrm{min}\right)$ & $\mathrm{R}^{2}$ & $\mathrm{~K}_{\mathrm{s}}\left(\mathrm{cm}^{2} / \mathrm{min}\right)$ & $\mathrm{R}^{2}$ \\
\hline 40 & 0,00037 & 0,9956 & 0,00037 & 0,9945 \\
\hline 50 & 0,00056 & 0,9881 & 0,00053 & 0,9937 \\
\hline 60 & 0,00077 & 0,9958 & 0,00069 & 0,9709 \\
\hline 67 & 0,00092 & 0,9864 & 0,00088 & 0,9977 \\
\hline
\end{tabular}

Os valores dos coeficientes de difusão $\left(\mathrm{K}_{\mathrm{s}}\right)$ foram relacionados com a temperatura por meio da equação de Arrhenius linearizada conforme mostrado na Equação 7. Por meio de regressão linear foi obtido o Parâmetro $E^{\prime}$ com $\mathrm{R}^{2}$ de 0,9942 e 0,9969 indicando adequado ajuste aos dados experimentais. A partir de $\mathrm{E}^{\prime}$ foram calculadas as energias de ativação, sendo $\mathrm{E}^{\prime}=\mathrm{E}_{\mathrm{a}} / \mathrm{R}$ e $\mathrm{R}$ é a constante universal dos gases e igual a $8,314 \mathrm{KJ} / \mathrm{mol} / \mathrm{K}$. Deste modo, os valores de $\mathrm{E}_{\mathrm{a}}$ obtidos foram de 29,91 KJ/mol para os milhos 2B587 e 27,81 KJ/mol para o milho $2 \mathrm{~B} 587 \mathrm{Hx}$. O milho convencional 2B587 obteve maior $E_{a}$ indicando que este grão experimentou maiores mudanças e o coeficiente de difusão foi mais influenciado pela variação de temperatura do que o milho 2B587 Hx.

$$
\ln K_{s}=\ln K_{0}-E^{\prime} \frac{1}{T}
$$


O tempo para os grãos alcançarem a condição de equilíbrio $\left(t_{e q}\right)$ pode ser definido como aquele no qual a umidade dos grãos atingem $99 \%$ da umidade de equilíbrio $\left(\rho_{A}=0,99 \rho_{\text {Aeq }}\right)$ conforme apresentado na Equação 8. Os tempos foram obtidos admitindo os valores médios das concentrações mássicas de equilíbrio $\left(\rho_{\text {Aeq }}\right)$ nas quatro temperaturas, utilizando-se $K_{s}=37,31 \exp$ ($3600,1 / T)$ para o milho 2B587 e Ks=16,37exp(-3347,7/T) para o milho 2B587 Hx. Os valores dos tempos em que os grãos atingem condições de equilíbrio variaram de 1348,8 a 571,99 minutos para o milho 2B587 que foram menores do que para o milho 2B587 Hx que variaram de 1414,9 a 622,62 minutos com a elevação da temperatura de 40 para $67^{\circ} \mathrm{C}$.

$$
t_{e q}=\frac{r_{0}}{3 K_{S}} \ln \left(\frac{100\left(\rho_{A e q}-\rho_{A 0}\right.}{\rho_{A e q}}\right)
$$

\subsection{Modelo para a Análise da Cinética de Sólidos Solúveis Liberados}

A Figura 3 mostra a liberação de sólidos solúveis na água de imersão dos dois milhos nas temperaturas de 40, 50, 60 e $67^{\circ} \mathrm{C}$. Pode-se observar que a liberação de sólidos ocorreu após 120 minutos e posteriormente aumentou de forma crescente durante a hidratação. Verificou-se que os dois grãos liberam quantidades de sólidos solúveis próximas entre si. O conteúdo de sólidos solúveis liberados nas temperaturas de 40 e $50{ }^{\circ} \mathrm{C}$ em 1710 minutos para os dois milhos foram em média de 3,4, enquanto que na temperatura de 60 e $67{ }^{\circ} \mathrm{C}$ aumentou para 5,6. Através da Equação 6 e por meio de regressão linear foram obtidos os valores de $\mathrm{k}_{\mathrm{ds}}$, conforme mostrado na Tabela 3 com valores de $\mathrm{R}^{2}$ variando de 0,8975 a 0,9438 . Observou-se que a taxa de liberação de sólidos solúveis apresentou forte influência da temperatura com a variação de 50 para $60{ }^{\circ} \mathrm{C}$.
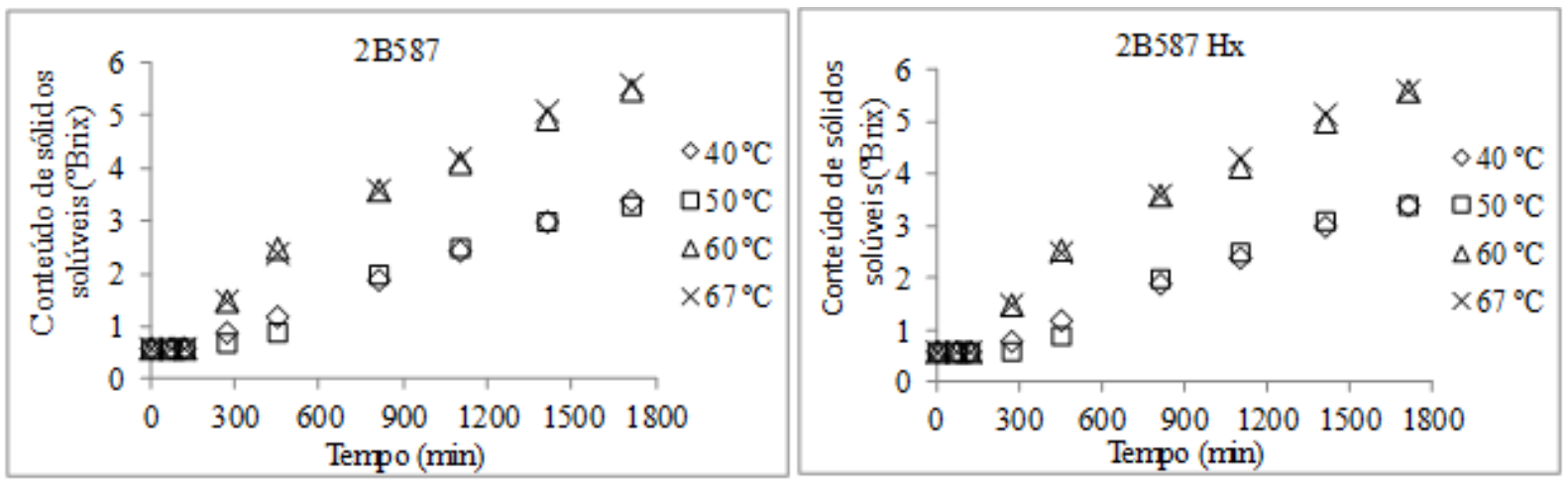

Figura 3 - Liberação de sólidos solúveis na água de imersão nas quatro temperaturas

Tabela 3 - Constante $\mathrm{k}_{\mathrm{ds}}$ para os dois milhos e seus coeficientes de determinação $\left(\mathrm{R}^{2}\right)$

\begin{tabular}{|c|c|c|c|c|}
\hline Temperatura $\left({ }^{\circ} \mathrm{C}\right)$ & \multicolumn{2}{|c|}{$2 \mathrm{~B} 587$} & \multicolumn{2}{c|}{$2 \mathrm{~B} 587 \mathrm{Hx}$} \\
& $\mathrm{k}_{\mathrm{ds}}(/ \mathrm{min})$ & $\mathrm{R}^{2}$ & & $\mathrm{R}^{2}$ \\
\hline 40 & 0,0020 & 0,9144 & 0,0020 & 0,9072 \\
\hline 50 & 0,0022 & 0,9134 & 0,0020 & 0,9072 \\
\hline 60 & 0,0037 & 0,8975 & 0,0037 & 0,9005 \\
\hline 67 & 0,0037 & 0,9438 & 0,0038 & 0,9396 \\
\hline
\end{tabular}


A constante $\mathrm{k}_{\mathrm{ds}}$ foi relacionada com a temperatura por meio da Equação de Arrhenius conforme mostrado na Equação 9 e E' foi obtido através de regressão linear para cada milho. Com estes valores foram calculadas as energias de ativação $\left(E_{a}\right)$ que foram de $23,20 \mathrm{KJ} / \mathrm{mol}$ para o milho $2 \mathrm{~B} 587$ e $24,78 \mathrm{KJ} / \mathrm{mol}$ para o milho $2 \mathrm{~B} 587 \mathrm{Hx}$ com $\mathrm{R}^{2}$ de 0,8829 e 0,8270 , respectivamente.

$$
\ln k_{d s}=\ln c-E^{\prime} \frac{1}{T}
$$

\section{CONCLUSÕES}

Neste trabalho foram observadas diferenças nas composições químicas entre as duas amostras. A velocidade de hidratação aumentou com a elevação da temperatura e o modelo de Parâmetros concentrados representou adequadamente o processo de hidratação dos grãos de milho. Os valores de $K_{s}$ variaram de 0,00037 a $0,00092 \mathrm{~cm}^{2} /$ min para o milho 2 B587 e 0,00037 a $0,00088 \mathrm{~cm}^{2} / \min$ para o milho $2 \mathrm{~B} 587 \mathrm{Hx}$. A relação de $\mathrm{K}_{\mathrm{s}}$ com a temperatura foi satisfatoriamente representada pela equação de Arrhenius obtendo-se energia de ativação (Ea) de 29,91 para o milho 2B587 e 27,81 KJ/mol para o milho $2 \mathrm{~B} 587 \mathrm{Hx}$. O modelo obteve ajuste adequado aos dados experimentais e constitui-se uma ferramenta útil para otimização das condições de hidratação dos milhos e projeto do processo. A liberação de sólidos solúveis apresentou forte influência da temperatura de imersão e o modelo cinético de ordem zero obteve boa qualidade de ajuste aos dados experimentais. Para a liberação de sólidos solúveis foi obtida energia de ativação de $23,20 \mathrm{KJ} / \mathrm{mol}$ para o milho 2B587 e 24,78 KJ/mol para o milho $2 \mathrm{~B} 587 \mathrm{Hx}$.

\section{NOMENCLATURA}

c constante da Equação de Arrhenius

E' Parâmetro da equação de Arrhenius (/K)

$\mathrm{K}_{0}$ Parâmetro pré-exponencial da equação de Arrhenius. $\left(\mathrm{cm}^{2} / \mathrm{min}\right)$

$\mathrm{k}_{\mathrm{ds}}$ constante da taxa de liberação de sólidos solúveis (/min)

$\mathrm{K}_{\mathrm{s}}$ Coeficiente de transferência de massa aparente $\left(\mathrm{cm}^{2} / \mathrm{min}\right)$

MS Massa do grão seco (g)

MU Massa do grão úmido $(\mathrm{g})$

$\mathrm{M}_{\mathrm{ds}} \quad$ sólidos liberados ( $\left({ }^{\circ} \mathrm{Brix}\right)$

$\mathrm{r}_{\mathrm{o}} \quad$ Raio inicial do grão $(\mathrm{cm})$

$\mathrm{T}$ Temperatura $\left({ }^{\circ} \mathrm{C}\right)$

t Tempo (min.)

$t_{\text {eq }}$ Tempo de equilíbrio (min.)

$\mathrm{X}_{\mathrm{bu}}$ Umidade em base úmida $(\mathrm{g} / \mathrm{g})$

$\rho_{\mathrm{A}}$ Concentração mássica de água $\left(\mathrm{g} / \mathrm{cm}^{3}\right)$

$\rho_{\text {Ao }}$ Concentração mássica inicial de água no grão $\left(\mathrm{g} / \mathrm{cm}^{3}\right)$

$\rho_{\text {Aeq }}$ Concentração mássica de água no grão no equilíbrio $\left(\mathrm{g} / \mathrm{cm}^{3}\right)$

$\rho_{\text {milho }}$ Densidade do grão $\left(\mathrm{g} / \mathrm{cm}^{3}\right)$

\section{REFERÊNCIAS}


AOAC. Association of Official Analytical Chemists. Official Methods of Analysis of the Association of Official Analytical Chemists (method 958.06). Arlington: A.O.A.C. v. 39. p. 21, 1995.

BALIEIRO NETO, G.; BRANCO, R. B. F.; CIVIDANES, T. M., dos S.; NOGUEIRA, J. R.; FELIX, M. R. F.; ROMA JUNIOR, L. C.; BUENO, M. S., FERRARI JÚNIOR, E.; POSSENTI, R.; REI, F. M. C. T. Relação custo benefício na produção de silagem com milho Bt. In: Clóves Cabreira Jobim; Ulysses Cecato; Marcos Weber do Canto. (Org.). Anais do IV Simpósio: Produção e Utilização de Forragens Conservadas. 1 ed. Maringá, PR, Brasil: Sthampa Gráfica e Editora, v. 1, p. 131-172, 2011.

BAYRAM, M.; KAYA, A.; ÖNER, M. D. Changes in properties of soaking water during production of soy-bulgur. J. Food Eng., v.61, p. 221-230, 2004.

CRUZ, J. C.; PEREIRA FILHO, I. A.; QUEIROZ, L. R. Milho - Cultivares para 2013/2014. Quatrocentas e sessenta e sete cultivares de milho estão disponíveis no mercado de sementes do Brasil para a safra 2013/2014. Embrapa Milho e sorgo. Disponível em: http://www.cnpms.embrapa.br/milho/cultivares/. Acesso em: março 2014.

INSTITUTO ADOLF LUTZ. Normas analíticas do Instituto Adolf Lutz, v.1, $3^{\mathrm{a}}$ ed., São Paulo: O Instituto, 1985.

INSTITUTO ADOLFO LUTZ. Métodos físico-químicos para análise de alimentos . 4ª ed. Brasília, Anvisa 2008. (item 044/IV).

LOPES FILHO, J. F.; RAMOS, A. P.; ROMERO, J. T. Difusividades da água, dióxido de enxofre e ácido lático em grãos de milho durante a maceração para o processo de moagem úmida. Braz. $J$. Food Technol., v. 9, n. 4, p. 257-263, 2006.

OMOTO, E. S.; ANDRADE, C. M. G.; JORGE, R. M. M.; COUTINHO, M. R.; PARAÍSO, P. R.; JORGE, L. M. M. Modelagem matemática e análise da hidratação de grãos de ervilha. Ciênc. $e$ Tecnol. de Aliment., v. 29, n. 1, p. 12-18, 2009.

PELEG, M. An empirical model for the description of moisture sorption curves. J. Food Sci., v. 53, p. 1216-1219, 1988.

PÉREZ, O. E., HAROS, M. and SUAREZ, C. Corn steeping: influence of time and lactic acid on isolation and thermal properties of starch. J. Food Eng., v. 48, p. 251-256, 2001.

SAXENA, D.; STOTZKY, G. Bt corn has a higher lignin content than non-Bt corn. Am. J. Bot. v. 88, n. 9, p. 1704-1706, 2001.

SAYAR, S.; TURHAN, M..; KÖKSEL, H. Solid loss during water absorption of chickpea (Cicer arietinum L.). J. Food Process Eng., v. 34, p. 1172-1186, 2011.

SHANDERA, D. L.; JACKSON, D. S. Effect of corn wet-milling conditions (sulfur dioxide, lactic acid and steeping temperature) on starch functionality. Cereal chem., v. 73, n. 5, p. 632-637, 1996 